\title{
Intraocular pressure reduction in chronic simple glaucoma by continuous infusion. of dilute pilocarpine solution
}

\author{
A. T. BIRMINGHAM, N. R. GALLOWAY, ${ }^{1}$ AND D. A. WALKER \\ From the Department of Physiology and Pharmacology, Medical School, Queen's Medical Centre, \\ Nottingham, and the ${ }^{1}$ Eye Hospital, Nottingham
}

SUMMARY Ten hospital outpatients with bilateral chronic simple glaucoma received a single drop of $2 \%$ pilocarpine to one eye and a continuous infusion of $0.1 \%$ pilocarpine at a flow rate of 0.01 $\mathrm{ml} / \mathrm{min}$ to the other eye (both solutions were at $\mathrm{pH} \mathrm{7 \cdot 2).} \mathrm{On} \mathrm{another} \mathrm{occasion} \mathrm{the} \mathrm{treatments} \mathrm{were}$ reversed. Measurements of intraocular pressure (IOP) and pupil diameter were made at 30 min intervals for 2 hours. The continuous infusion of dilute solution was as effective as the single drop of more concentrated solution in reducing IOP and in constricting the pupil; the drop was somewhat faster in producing its effect.

It has previously been shown in normal persons that the technique of continuous infusion of a dilute solution of pilocarpine at a rate which does not produce overflow from the conjunctival sac can be as effective as a pupilloconstrictor as a single drop of a more concentrated solution (Birmingham et al., 1976a). We now report an investigation of the effectiveness of continuous infusion of dilute pilocarpine in lowering the intraocular pressure in elderly hospital outpatients with chronic simple glaucoma. A preliminary account of this work has been presented elsewhere (Birmingham et al., 1976b).

\section{Patients and methods}

The subjects were 10 outpatients of the Glaucoma Clinic at Nottingham Eye Hospital who had a diagnosis of bilateral chronic simple glaucoma which was controlled by pilocarpine eye drops. There were 6 men and 4 women and their ages ranged from 63 to 83 years (mean 71.4 years). They gave their informed consent to participate in a comparison of the effect of a single drop of $2 \%$ pilocarpine at $\mathrm{pH} 7.2$ with that of an infusion at $0.01 \mathrm{ml} / \mathrm{min}$ of $0.1 \%$ pilocarpine at $\mathrm{pH} 7 \cdot 2$. A cross-over design was used so that each eye received

Correspondence to Professor A. T. Birmingham, Department of Physiology and Pharmacology, Medical School, Queen's Medical Centre, Nottingham NG7 2UH. the single drop on one occasion and the infusion on another.

The patients were asked to attend the clinic on 3 separate occasions at weekly intervals. The time of day was the same for each visit to minimise any effect of diurnal variation. At the first visit the patients were on their usual treatment, and 3 measurements of intraocular pressure (IOP) of both eyes were made at $30 \mathrm{~min}$ intervals to establish controlled baseline IOP. The patients were asked to stop using their drops for the 3 days preceding each of the next 2 visits. At the second visit, after 1 measurement of IOP and pupil diameter of each eye, an infusion of $0.1 \%$ pilocarpine at $0.01 \mathrm{ml} / \mathrm{min}$ was begun to the right eye and a single drop of $2 \%$ pilocarpine was administered to the left eye. The infusion was continued for 2 hours and readings of IOP and pupil diameter were made for both eyes at 30 min intervals. At the third visit the procedure followed during the second visit was repeated except that the right eye received the single drop administration and the left eye received the continuous infusion. At the end of the third visit the patients were told to return to their usual treatment.

Five healthy volunteers with no history of eye disease except mild refractive errors, who did not wear contact lenses, took part in a separate investigation of the effects on bilateral pupil diameter of an infusion of $0.1 \%$ pilocarpine at $\mathrm{pH} 7.2$ for 2 hours into the left eye. Pupil diameter was measured every $5 \mathrm{~min}$. 
MEASUREMENT OF INTRAOCULAR PRESSURE AND PUPIL DIAMETER

For the patients at the Glaucoma Clinic the IOP was measured by applanation tonometry (Goldmann tonometer) under $0.5 \%$ proparacaine local anaesthesia. Pupil diameter was measured by direct observation through the calibrated graticule of the telescope of a Goldmann perimeter under controlled white light illumination.

In the normal volunteers the pupil diameter was measured under low intensity red light illumination in a dark room. The pupil was observed through a low-power binocular microscope $(\times 5$ eyepieces, $\times 1.25$ objectives) suspended above the eye. One eyepiece was fitted with a graticule to allow direct measurement of the diameter of the pupil in the field of view.

\section{INFUSION TECHNIQUE}

This was identical to that described by Birmingham et al. (1976a). The solution was contained in a sterile $1 \mathrm{ml}$ syringe compressed by a motor driven syringe ram at a rate to provide a flow of $0.01 \mathrm{ml} /$ min. The fluid was delivered to the conjunctival sac of the eye being infused by means of sterile smallbore silicone elastomer tubing (Silastic No. 602-101, Dow Corning) of about $2 \mathrm{~m}$ length. The distal end of the tubing rested in the inner canthus of the eye and was held in place by adhesive tape attached to the nose and forehead.

When a patient needed to move between rooms at $\frac{1}{2}$-hourly intervals for measurements of IOP and pupil diameter, the infusion was briefly interrupted and the syringe was temporarily removed from the syringe ram and clipped to the patient's clothing.

\section{PILOCARPINE SOLUTIONS AND DOSES}

The sterile solutions of pilocarpine hydrochloride were specially formulated to a $\mathrm{pH}$ of $7 \cdot 2$ by the addition of borate buffer. Owing to the much shorter shelf life of pilocarpine at near neutral $\mathrm{pH}$ than at its natural more acid pH (Riegelman and Vaughan, 1958; Cowle and Anderson, 1967) the solution was provided in 2 bottles, the contents of which were mixed immediately before use. One bottle contained the pilocarpine solution at its natural $\mathrm{pH}$ at twice the final concentration required, the other bottle contained an equal volume of an appropriate borate buffer and sodium chloride solution. On mixing the 2 solutions, a sterile solution, isotonic with tears, having a $\mathrm{pH}$ of $7 \cdot 2$ and pilocarpine concentration of $2 \%$ or $0.1 \%$ was obtained.

After the recording of baseline measurements the patients received one drop $(0.05 \mathrm{ml})$ of $2 \%$ pilocarpine (dose $1 \mathrm{mg}$ ) to one eye and the infusion of $0.1 \%$ pilocarpine at $0.01 \mathrm{ml} / \mathrm{min}$ (dose $1 \mathrm{mg}$ after $100 \mathrm{~min}$ ) to the other eye. This procedure was reversed for the 2 eyes on the third visit.

The normal subjects received only the $0.1 \%$ pilocarpine infusion to the left eye on 1 occasion.

\section{Results}

COMPARISON OF THE OCULAR HYPOTENSIVE EFFECTS OF PILOCARPINE AT PH $7 \cdot 2$ GIVEN AS A SINGLE DROP OR AS AN INFUSION The means of the 3 measurements of IOP made on both eyes when the 10 patients were on their usual treatment for their glaucoma were $18.8 \mathrm{mmHg}$ for right eyes and $19 \cdot 1 \mathrm{mmHg}$ for left eyes (Table 1). After stopping the treatment for 3 days, on 2 occasions at weekly intervals, the IOP rose in both eyes. The rise in pressure in the right eyes was. statistically significant; the rise in pressure in the left eyes was smaller and did not achieve statistical significance (Table 1).

The single drop of $2 \%$ pilocarpine and the continuous infusion of $0.1 \%$ pilocarpine reduced the IOP of both eyes and the effect increased with time over the period of observation (Fig. 1). At each $30 \mathrm{~min}$ point of measurement after the start of treatment the means of the differences between pretreatment measurements and post-treatment measurements for either the single drop or the continuous infusion were statistically significant (Table 2). When the effects of the 2 treatments were compared, the degree of fall in pressure at each time of measurement was the same in the left eyes whether they had received the drop or the infusion. For the right eyes the fall in pressure was greater at 30 and at $60 \mathrm{~mm}$ for the drop compared with the infusion (this difference was statistically significant

Table 1 Means (with one standard deviation) for right and left eyes $(n=10)$ of intraocular pressure measurements made while taking standard treatment and after interrupting treatment for 3 days

\begin{tabular}{llll}
\hline & $\begin{array}{l}\text { 1st Visit, } \\
\text { While receiving } \\
\text { usual drops }\end{array}$ & $\begin{array}{l}\text { 2nd Visit, } \\
\text { 3 days after } \\
\text { stopping drops }\end{array}$ & $\begin{array}{l}\text { 3rd Visit, } \\
\text { 3 days after } \\
\text { stopping drops }\end{array}$ \\
\hline $\begin{array}{c}\text { Right eyes } \\
(\mathrm{n}=10)\end{array}$ & $18 \cdot 8(4 \cdot 5)$ & $24 \cdot 7(5 \cdot 8)$ & $25 \cdot 3(5 \cdot 1)$ \\
$\begin{array}{c}\text { Left eyes } \\
(\mathrm{n}=10)\end{array}$ & $19 \cdot 1(3.9)$ & $21 \cdot 3(3.3)$ & $22 \cdot 4(3.0)$ \\
\hline \hline
\end{tabular}

Differences (paired $\mathrm{t}$ tests) between:

\begin{tabular}{lll}
\hline & 1st and 2nd Visits & 1st and 3rd Visits \\
\hline Right eyes & $0.02>\mathrm{P}>0.01$ & $0.02>\mathrm{P}>0.01$ \\
Left eyes & $0.2>\mathrm{P}>0.1$ & $0.1>\mathrm{P}>0.05$ \\
\hline
\end{tabular}


only at $60 \mathrm{~min}$ ) but was not greater at 90 and 120 min. Thus it appears that the rate of effect and the degree of effect of the 2 treatments were the same in left eyes, whereas in right eyes the rate of onset of effect was greater for the single drop but the eventual degree of effect was no different from that achieved by the infusion.

Pilocarpine in Chronic Simple Glaucoma
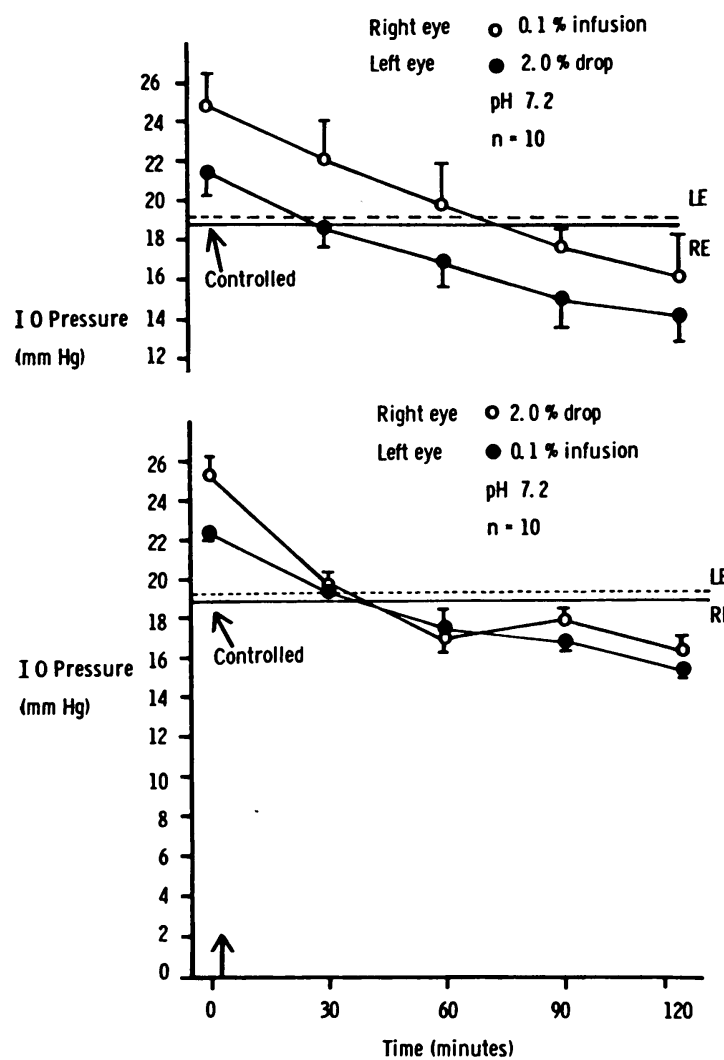

Fig. 1 Means $( \pm S E M)$ of intraocular pressures of the eyes of 10 patients with bilateral chronic simple glaucoma. The pressure at zero time was that recorded, after 3 days with no treatment, immediately preceding the instillation of 1 drop containing $1 \mathrm{mg}$ pilocarpine at $\mathrm{pH} 7.2$ or the start of an infusion of a $0.1 \%$ solution of pilocarpine at $10 \mu \mathrm{g} / \mathrm{min}$ at $\mathrm{pH} 7 \cdot 2$. Treatments were reversed between first (upper graph) and second (lower graph) sets of measurements, which were separated by an interval of 1 week. Intraocular pressure was measured every $30 \mathrm{~min}$. The solid horizontal lines indicate the means of the controlled intraocular pressures of right eyes $(R E)$ on regular treatment with pilocarpine drops and the broken horizontal lines those for left eyes $(L E)$
EFFECT ON PUPIL DIAMETER

For the patients the effect of either treatment was to reduce pupil diameter. This reduction was statistically significant at the first post-drug measurement at $30 \mathrm{~min}$ for all eyes and remained so for the next 3 measurements (Table 3 ). When the treatments were compared, there was a significantly greater pupilloconstrictor effect from the drop than from the infusion in left eyes at $60 \mathrm{~min}$ only and in right eyes at 60 and at $90 \mathrm{~min}$ (notes a, b, and c, Table 3).

For the 5 normal subjects an infusion of $0.1 \%$ pilocarpine to the left eye rapidly reduced pupil diameter to a mean of some $30 \%$ of control diameter by $50 \mathrm{~min}$ after the start of the infusion. This reduction persisted until the cessation of the infusion. Throughout the $120 \mathrm{~min}$ of infusion to the left eyes there was no change in diameter of the pupils of the untreated right eyes.

\section{Discussion}

From this comparison of 2 methods of administering pilocarpine the general conclusion seems to be that a continuous infusion of a dilute solution is as effective as a single drop of a more concentrated solution. For a fair comparison of the 2 methods it was necessary to administer the same dose to each eye. When the interruptions of the infusion which were necessary for IOP and pupil diameter measurements are taken into account, the dose delivered by the $2 \%$ drop or the $0.1 \%$ infusion was the same at $1.0 \mathrm{mg}$. Because of the pronounced influence of $\mathrm{pH}$ on pilocarpine absorption (Anderson and Cowle, 1968; Birmingham et al., 1976a) it was necessary to make the $\mathrm{pH}$ of both the concentrated drop and the dilute infusion the same $(\mathrm{pH} \mathrm{7.2)}$ at a value close to that of tears.

It is unlikely that the patients' usual treatment was still exerting an effect 3 days after stopping the drops. Drance et al. (1974) showed that $15 \mathrm{~h}$ after the high dose of a drop of $8 \%$ pilocarpine the IOP had returned to within $90 \%$ of the pre-drug value. After stopping the usual treatment for 3 days the expected difference in pressure between the 2 eyes was found. Davanger (1965) in an extensive study reported a mean difference in pressure between the 2 eyes of patients with glaucoma of $2.8 \mathrm{mmHg}$. In the present small series the mean differences were $3.4 \mathrm{mmHg}$ at the second visit and $2.9 \mathrm{mmHg}$ at the third visit.

The appropriateness of a $2 \mathrm{~h}$ period for the measurement of the effects of the treatments is supported by the finding of Drance and Nash (1971), who measured the effect of $2 \%$ pilocarpine for 8 hours but found the effect to be maximal at 2 hours. Fenton and Schwartz (1963) found the 
Table 2 Means (with standard deviation) for the right and left eyes of differences between $\mathrm{IOP}(\mathrm{mmHg})$ after interrupting treatment for 3 days and IOPs at 30,60, 90, and 120 min after beginning of infusion or application of drop. The same 10 patients attended for the 2 nd and 3 rd visits

\begin{tabular}{|c|c|c|c|c|}
\hline \multicolumn{5}{|c|}{ 2nd Visit } \\
\hline & $30 \min$ & $60 \min$ & $90 \min$ & $120 \mathrm{~min}$ \\
\hline Right eyes $(n=10)(0.1 \%$ infusion $)$ & $2 \cdot 6(3.0)$ & $4.9(2 \cdot 8)$ & $7 \cdot 3(3 \cdot 4)$ & $8 \cdot 7(2 \cdot 6)$ \\
\hline Paired t-test & $0.025>P>0.02$ & $\mathbf{P}<0.001$ & $P<0.001$ & $P<0.001$ \\
\hline Left eyes $(n=10)(2.0 \%$ drop $)$ & $2 \cdot 5(3 \cdot 1)$ & $4 \cdot 3(2 \cdot 3)$ & $6 \cdot 3(3 \cdot 8)$ & $7 \cdot 0(4 \cdot 0)$ \\
\hline Paired t-test & $0.05>P>0.025$ & $\mathrm{P}<0.001$ & $\mathrm{P}<0.001$ & $\mathbf{P}<0.001$ \\
\hline \multicolumn{5}{|c|}{ 3rd Visit } \\
\hline & $30 \mathrm{~min}$ & $60 \mathrm{~min}$ & $90 \mathrm{~min}$ & $120 \min$ \\
\hline Right eyes $(n=10)(2.0 \%$ drop $)$ & $5 \cdot 8(6 \cdot 6)$ & $8 \cdot 3(4 \cdot 5)$ & $7 \cdot 5(4 \cdot 8)$ & $9 \cdot 0(4 \cdot 7)$ \\
\hline Paired t-test & $0.025>P>0.02$ & $\mathbf{P}<0.001$ & $P<0.001$ & $\mathbf{P}<0.001$ \\
\hline Left eyes $(n=10)(0 \cdot 1 \%$ infusion $)$ & $2 \cdot 7(3.4)$ & $5.0(3.9)$ & $5 \cdot 8(3 \cdot 2)$ & $7 \cdot 1(3 \cdot 5)$ \\
\hline Paired t-test & $0.05>P>0.025$ & $0.005>P>0.001$ & $P<0.001$ & $\mathrm{P}<0.001$ \\
\hline
\end{tabular}

Table 3 Means (with one standard deviation) for right and left eyes of pupil diameters (mm) after interrupting treatment for 3 days and at 30, 60, 90, and 120 min after beginning of infusion or application of drop. The same 10 patients attended for the 2 nd and 3 rd visits

\begin{tabular}{|c|c|c|c|c|c|}
\hline \multicolumn{6}{|c|}{ 2nd Visit } \\
\hline & \multirow[b]{2}{*}{ Pre-drug } & \multicolumn{4}{|c|}{ Time after exposure to drug } \\
\hline & & $30 \mathrm{~min}$ & $00 \mathrm{~min}$ & $90 \mathrm{~min}$ & $120 \min$ \\
\hline Right eyes $(n=10)(0.1 \%$ infusion $)$ & $3 \cdot 3(0 \cdot 6)$ & $2 \cdot 2(0 \cdot 6)$ & $2 \cdot 1(0 \cdot 5)$ & $2 \cdot 0(0 \cdot 5)$ & $1.9(0.5)$ \\
\hline Paired t-test & & $P<0.001$ & $P<0.001$ & $P<0.001$ & $P<0.001$ \\
\hline Left eyes $(n=10)(2.0 \%$ drop $)$ & $3 \cdot 2(0 \cdot 7)$ & $2 \cdot 3(0 \cdot 8)$ & $1.9(0 \cdot 7)^{\mathrm{a}}$ & $1.9(0 \cdot 7)$ & $1.9(0 \cdot 7)$ \\
\hline Paired t-test & & $0.02>\mathrm{P}>0.01$ & $0.005>P>0.001$ & $0.005>\mathrm{P}>0.001$ & $0.005>P>0.001$ \\
\hline \multicolumn{6}{|c|}{ 3rd Visit } \\
\hline Right eyes $(n=10)(2.0 \%$ drop $)$ & $3 \cdot 3(0 \cdot 7)$ & $1.9(0.6)$ & $1 \cdot 7(0 \cdot 5)^{\mathrm{b}}$ & $1 \cdot 7(0 \cdot 5)^{\mathrm{c}}$ & $1 \cdot 7(0 \cdot 5)$ \\
\hline Paired t-test & & $P<0.001$ & $P<0.001$ & $P<0.001$ & $\mathbf{P}<0.001$ \\
\hline Left eyes $(n=10)(0.1 \%$ infusion $)$ & $3 \cdot 2(0 \cdot 5)$ & $2 \cdot 6(0 \cdot 6)$ & $2 \cdot 3(0 \cdot 6)$ & $2 \cdot 2(0 \cdot 6)$ & $2 \cdot 1(0 \cdot 7)$ \\
\hline Paired t-test & & $0.005>P>0.001$ & $P<0.001$ & $0.005>P>0.001$ & $0.005>P>0.001$ \\
\hline
\end{tabular}

Within eyes there was a significantly greater pupilloconstrictor effect of the $2 \%$ drop compared with the $0 \cdot 1 \%$ infusion at 60 min (a, $0.05>P>0.025 ; b, P<0.001)$ for both eyes and at $90 \mathrm{~min}(\mathrm{c}, 0.025>\mathrm{P}>0.02)$ for right eyes.

effect of $2 \%$ pilocarpine to reach 'a steady state' at 75 min in 10 patients with glaucoma. Thus in the present investigation the effect of the infusion was compared at 2 hours with the likely maximal effect of the single drop. At the end of this 2 hour period the hypotensive effect of the 2 treatments was similar: in right eyes the mean falls in IOP were $8.7 \mathrm{mmHg}$ for the infusion and $9.0 \mathrm{mmHg}$ for the drop, in left eyes the corresponding values were
$7 \cdot 1$ and $7 \cdot 0 \mathrm{mmHg}$. The rate of achievement of this fall was greater for the drop than for the infusion in right eyes but the same in left eyes.

Change in pupil diameter was measured as another index of entry of drug into the eye. Again the effect of the 2 treatments was similar at the end of 2 hours: in right eyes the mean pupilloconstrictor effects were $1.4 \mathrm{~mm}$ for the infusion and $1.6 \mathrm{~mm}$ for the drop, while the corresponding figures for 
left eyes were 1.1 and $1.3 \mathrm{~mm}$. During the 2 hour period the greater effect of the drop at $60 \mathrm{~min}$ (both eyes) and at $90 \mathrm{~min}$ (right eyes only) suggests a faster rate of effect for the drop.

It is not surprising that there were some differences in the rate of onset of effect. Although the final dose at the end of 2 hours was the same, the initial concentration produced by the $2 \%$ drop would be higher than that produced by the $0.1 \%$ infusion. Schumacher (1966) found that pilocarpine (pH 4.2) could be detected in the aqueous of rabbits within 3-5 min of instillation of a single drop into the conjunctival sac. Van Hoose and Leaders (1974) suggested that the release of drug from the endothelial surface of the cornea depended on the concentration of the drug to which the cornea was exposed. The cornea was seen to act as a reservoir for the drug. The effectiveness of a $2 \%$ drop will decline after 2 hours (Drance and Nash, 1971), whereas that of an infusion will continue for as long as the infusion is continued.

The observations on the time course of the effects of a single drop or an infusion on IOP and pupil diameter in patients with glaucoma are consistent with those for pupil diameter in normal subjects. Birmingham et al. (1976a) found the maximum effect of a single drop of $0.5 \%$ pilocarpine to be the same as that of an infusion of $0.01 \%$ pilocarpine but to occur $30 \mathrm{~min}$ earlier.

The study of the effects of administering pilocarpine to 1 eye showed that there was no detectable effect of that administration on the contralateral untreated eye. It seemed justifiable therefore to investigate different treatments to each of the 2 eyes on 1 occasion in the knowledge that there would be little or no interference between eyes.

We conclude from our results that a continuous infusion of a dilute solution of pilocarpine into the conjunctival sac is as effective in lowering the IOP in glaucoma as a more concentrated solution administered as a drop. The use of dilute solutions of pilocarpine would seem to be likely to reduce the possibility of systemic toxicity. To the advantage of the continuous maintenance by the infusion of an effective concentration in the eye for as long as the infusion is continued may be added the reduction in disturbance of the patient and the reduced nursing time compared with the frequent administration of drops. The principle of continuous infusion is obviously applicable to drugs other than pilocarpine. The use of a small body-borne infusion device allows the patient some degree of mobility during treatment (Bedford et al., 1976).

We thank the patients who co-operated in this investigation and the nursing staff of Nottingham Eye Hospital for their help and forbearance.

\section{References}

Anderson, R. A., and Cowle, J. B. (1968). Influence of pH on the effect of pilocarpine on aqueous dynamics. British Journal of Ophthalmology, 52, 607-611.

Bedford, G. J., Birmingham, A. T., and Galloway, N. R. (1976). Continuous infusion of the conjunctival sac with chloramphenicol in preoperative cataract patients. Transactions of the Ophthalmological Societies of the United Kingdom, 96, 325-326.

Birmingham, A. T., Galloway, N. R., and Spencer, S. A. (1976a). A comparison of the pupilloconstrictor effect of pilocarpine solution administered to the conjunctival sac as a single drop or as a continuous infusion in normal subjects. British Journal of Ophthalmology, 60, 568-572.

Birmingham, A. T., Galloway, N. R., Spencer, S. A., and Walker, D. A. (1976b). Continuous infusion of the conjunctival sac with pilocarpine in normal subjects and in patients with chronic glaucoma. Transactions of the Ophthalmological Societies of the United Kingdom, 96, 322-324.

Cowle, J. B., and Anderson, R. A. (1967). Dose-response relationships for the clinical and pharmaceutical evaluation of glaucoma drugs. Transactions of the Ophthalmological Society of Australia, 26, 110-113.

Davanger, M. (1965). The difference in ocular pressure in the two eyes of the same person: in individuals with healthy eyes and in patients with glaucoma simplex. Acta Ophthalmologica, 43, 299-313.

Drance, S. M., Benstead, M., and Schulzer, M. (1974). Pilocarpine and intraocular pressure: duration of effectiveness of $1 \%$ and $8 \%$ pilocarpine instillation. Archives of Ophthalmology, 91, 104-106.

Drance, S. M., and Nash, P. A. (1971). The dose response of human intraocular pressure to pilocarpine. Canadian Journal of Ophthalmology, 6, 9-13.

Fenton, R. H., and Schwartz, B. (1963). The effect of 2 per cent pilocarpine on the normal and glaucomatous eye. I. The time response of pressure. Investigative Ophthalmology, 2, 289.

Riegelman, S., and Vaughan, D. G. (1958). A rational basis for the preparation of ophthalmic solutions. Journal of the American Pharmaceutical Association, Practical Pharmacy Edition, 19, 537-540.

Schumacher, H. (1966). Die Bedeutung von Applickationsform und Konzentration für die Verweildauer von Pilocarpin und Eserin im Conjunctivalsack und im Kammerwasser. Albrech von Graefes Archiv für klinische und experimentelle Ophthalmologie, 169, 160-165.

Van Hoose, M. C., and Leaders, F. E. (1974). The role of the cornea in the biologic response to pilocarpine. Invest $i$ gative Ophthalmology, 13, 377-383. 